\title{
An Empirical Correlation for Zero-Net Liquid Flow in Gas-Liquid Compact Separator
}

\author{
Sunday Kanshio \\ Department of Petroleum and Gas Engineering, Baze University, Abuja, Nigeria \\ Email address: \\ sunday.kanshio@bazeuniversity.edu.ng \\ To cite this article: \\ Sunday Kanshio. An Empirical Correlation for Zero-Net Liquid Flow in Gas-Liquid Compact Separator. American Journal of Chemical \\ Engineering. Vol. 7, No. 3, 2019, pp. 81-89. doi: 10.11648/j.ajche.20190703.11
}

Received: August 6, 2019; Accepted: August 21, 2019; Published: September 3, 2019

\begin{abstract}
Compact separators have significant application for subsea separation and offshore application. However, their operating envelope is usually narrow due to physical phenomena such as liquid carryover and gas carry-under. Before the occurrence of liquid carryover, the separator operates in what is termed zero-net liquid flow (ZNLF). Though there is an efficient separation during ZNLF; there is also liquid holdup in the upper section of the separator, which is termed as ZNLF holdup. The ZNLF holdup in a cyclonic separator during an actual gas-liquid separation was studied experimentally. The ZNLF holdup was measured directly using electrical resistance tomography (ERT). The direct measurement approach is an improvement of the existing method, which depends on measuring the pressure drop across the stagnant liquid column. The results showed that increasing gas flow rate at a constant liquid flow rate increase zero-net liquid holdup in the upper part of the separator. An empirical correction was developed, and the correlation predicted the experimental results with a $\pm 10 \%$ error margin. The correlation could be useful as part of the input into a pressure drop model for calculating pressure drop across the gas leg of the cylindrical cyclonic separator. This correlation will be useful to process engineers for optimum design and operation of a gas-liquid compact separator.
\end{abstract}

Keywords: Gas-liquid Separator, Zero-net Liquid Flow, Liquid Holdup, Liquid Carry-over, Oil and Gas Production

\section{Introduction}

Traditionally, gravity separators are used in the oil field for splitting the produced fluids into gas, oil and water. However, gravity separators are usually bulky and heavy; hence not appropriate for use where space and weight are design constraints. Gas-liquid compact separator designed to operate based on the cyclonic separation principle is now gaining momentum in the petroleum industry, especially in situations where equipment weights and installation space are design constraints. A good example of such a situation includes subsea separation, offshore production platforms, downhole separation, metering skids, well-testing, and underbalanced drilling [1-5]. However, these compact separators suffer the disadvantage of a narrow operating envelope for liquid carryover (LCO). To understand the conditions at which LCO occur requires a good knowledge of the hydrodynamic phenomena in the upper section of the separator. During the normal operating condition of a gas-liquid cyclonic separator, the liquid can exist in the upper part of the separator in the form of swirling liquid film or droplets as shown graphically in Figure 1. One hydrodynamic phenomenon that is associated with LCO is termed zero-net liquid flow. The separator is said to experience a zero-net liquid flow (ZNLF) when two-phase flow exists in the upper part of the separator without any liquid droplets flowing out with the gas stream. The area-average cross-sectional liquid fraction at any fixed position in the upper part of the separator during ZNLF is referred to as zero-net liquid holdup (ZNLH). Research has shown that for every inlet gas flowrate, there is a corresponding threshold of liquidholdup in the upper section of the separator that allows the gas to flow through without picking some liquid droplets out of the separator [7]. If the gas flow rate exceeds that threshold, liquid carryover will occur, but below the threshold, liquid carryover will not take place. 


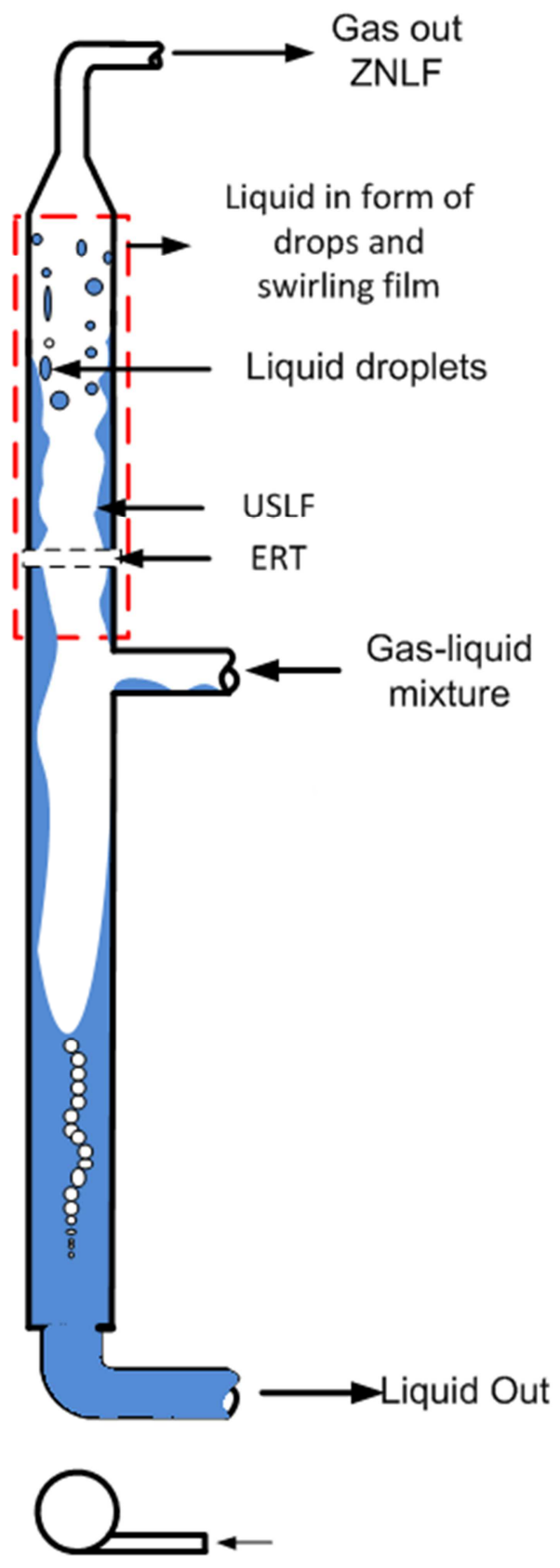

Figure 1. Schematic illustration of ZNLF GLPC separator.

There are few existing works on the use of advance flow measurement instrument to obtain average liquid holdupunder ZNLF condition. Kouba et al., [8] used a stagnant liquid approach for measuring liquid holdup in the region above the inlet of the gas-liquid cyclonic separator. This procedure involved filling the separator with liquid while the liquid exit line remained shut and introducing a known gas flow into the stagnant liquid column to blowout a certain amount of the liquid out of the separator to a point where the gas can no longer transport any drop of liquid out of the separator. The remaining liquid churns up and down as the gas bubbles through it, and the liquid holdup under this condition is obtained by differential pressure measurement or by liquid volume trap method. This approach is simple, cheap and assumed that no gas bubbles exist in the stagnant liquid column during measurements. Considering the fact that no liquid is flowing into the separator and separation is not taking place; liquid holdup obtained using this approach may not be the true picture of the ZNLH under two-phase flow at the separator inlet. Kouba et al., [8] also measured ZNLF holdup without stopping the system (under flowing condition) using the differential pressure method. This method ignores frictional pressure drop due to fluid momentum at the inlet nozzle. However, frictional pressure drop at the entrance of cyclonic separator, especially at high gas flow rate could be significant and affect the liquid holdup in the upper part of the separator.

However, during the actual separation process, it is obvious that ZNLF phenomena exist in the separator for every combination of inlet gas and liquid superficial velocity. Unfortunately, it may be impossible to study ZNLF at various inlet gas and liquid superficial velocities using the existing approach. Though recently, Kolla et al., conducted an experiment and obtained zero-net liquid holdup under actual separator operating condition [9]. However, they used a similar method as Kouba and Arpardi to obtain the zero-net liquid holdup. Kolla et al., also modified Wallis model to predict the zero-net liquid holdup [9]. The present work has extended the existing research by using wire mesh sensor, electrical resistance tomography and differential pressure sensor to measure ZNLF holdup for various test points during the phase separation process. A dimensional analysis approach was used in the present work to develop an empirical model for estimating the zero-net liquid holdup.

\section{Description of Experimental Set-up and Procedures}

\subsection{Description of the Facility}

The experiment was conducted in a $76.2 \mathrm{~mm}$ ID and $2.7 \mathrm{~m}$ tall gas-liquid pipe cyclone (GLPC) separator test facility at Cranfield University, UK. As shown in Figure 2, the test facility is a closed loop system consisting of fluids supply and metering section, GLPC separator and fluids return section. Air and water were used as test fluids and referred to as gas and liquid, respectively in the remaining parts of this article. Liquid and gas from the fluid supply via a metering section enter the mixing point to form a two-phase mixture. From the fluids mixing point, the two-phase mixture enters the GLPC separator where the mixture is separated into liquid and gas. Finally, the separated liquid returned to the storage tank while the gas is vented out.

The total length of the flow loop upstream of the GLPC separator is approximately $27.62 \mathrm{~m}$ long. The required air is metered using Endress+Hauser thermal mass flow meter (Proline t-mass 65) before entering the flow loop. Water is supplied to the flow loop by Certikin Aquaspeed self-priming pump which has a maximum duty of $4 \mathrm{l} / \mathrm{s}$ at $3 \mathrm{barg}$. It is metered using $\mathrm{ABB}$ electromagnetic flow meter. The test area consists mainly of the GLPC separator (with associated 
instrumentation) where the separation of gas from the liquid takes place. The gas outlet pipe is 1" while the liquid outlet is 2 " pipe. A gate valve is installed on the gas and liquid outlet for manual control of separator pressure and flow rate, respectively. Upon separation, the liquid and gas return back to an open tank which has a dimension of W1.2 $\times \mathrm{H} 1.2 \times$ $\mathrm{L} 1.2 \mathrm{~m}^{3}$.

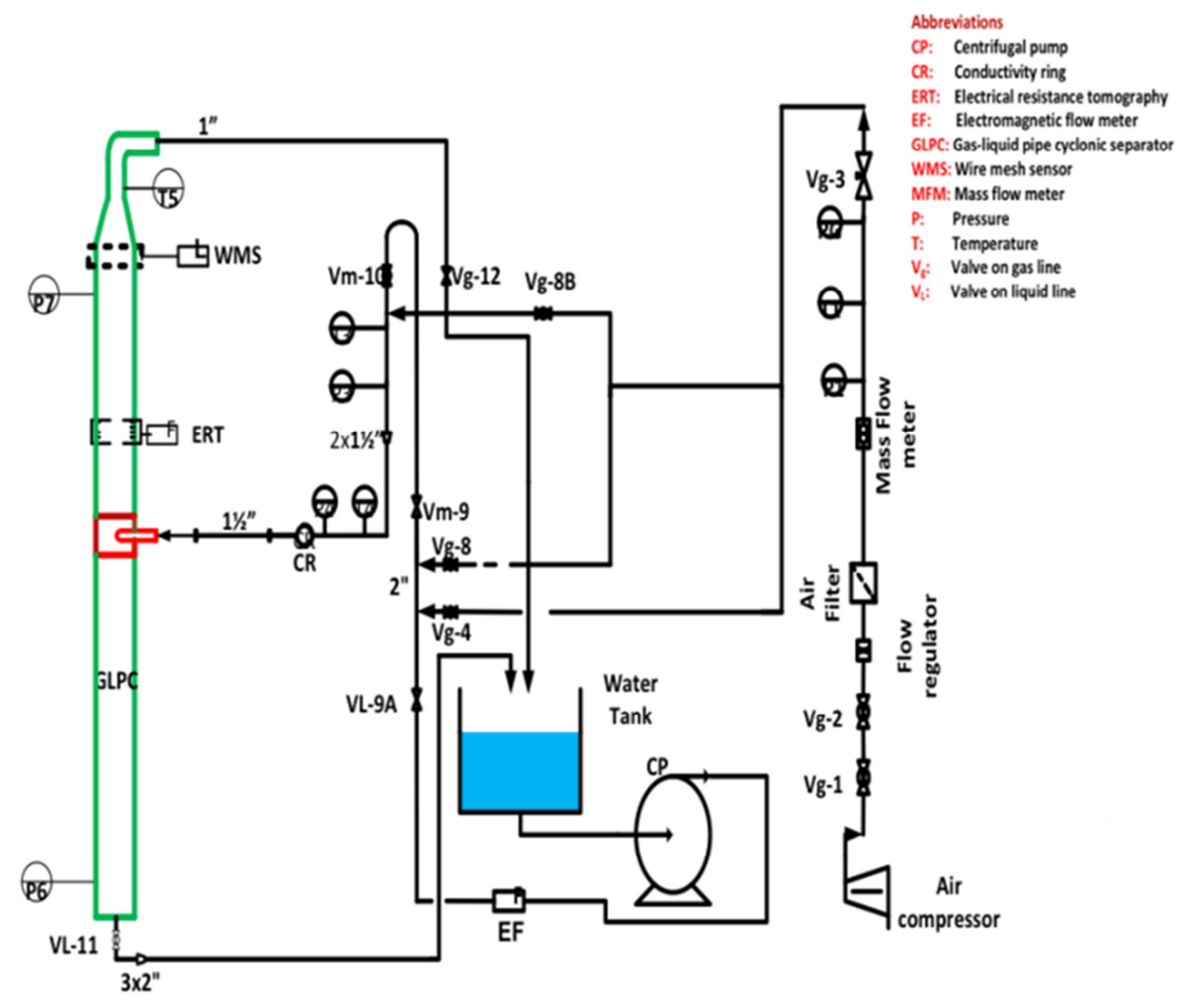

Figure 2. Experimental Set-up of a GLPC separator.

\subsection{Instruments}

The instruments used in this study were electrical resistance tomography (ERT), wire mesh sensor (WMS), pressure transducer, conductivity ring and, temperature probe. The liquid holdup in the section above the separator inlet was measured using electrical resistance tomography (ERT) made by ITS Ltd. ERT is a non-intrusive measurement technique by which information about the electrical properties of fluids in a process vessel or pipeline is inferred from the periphery electrode measurement. The ERT used in this study consist of a dual-plane sensor each having 16 stainless steel electrodes mounted on the periphery of the GLPC separator. A data acquisition system (DAS) was used to acquire data from the sensor. The data acquisition and transfer speed of the system was approximately 1000 dual frames per second. The sensitive coefficient back projection algorithm was used for image reconstruction.

\subsection{Experimental Procedures}

Vertical upward swirling two-phase flow experiment: This experiment was carried out to compare liquid holdup measurement of ERT with that of WMS. The liquid outlet was completely shut, and the gas outlet of the separator was fully open so that vertical two-phase flow was achieved. The flowrate of liquid was fixed at 0.22 and $0.70 \mathrm{~m} / \mathrm{s}$ while gas flowrate was varied from $0.12 \mathrm{~m} / \mathrm{s}$ to $2.4 \mathrm{~m} / \mathrm{s}$ and 0.16 to 3.9 $\mathrm{m} / \mathrm{s}$ respectively. When a steady two-phase was established, ERT, WMS and LabVIEW data were acquired respectively.

Stagnant liquid experiment: The separator was initially filled with liquid after which the liquid exit line was shut to keep the liquid in separator stagnant. The gas outlet line was left fully open; $0.54 \mathrm{~m} / \mathrm{s}$ of gas was injected into the separator to blow out the liquid until ZNLF was established before data acquisition. The gas velocity was then varied to a maximum of $10.2 \mathrm{~m} / \mathrm{s}$, and the data for each condition were recorded.

Phase Separation experiment: This experiment was conducted under actual separation condition whereby both liquid and gas exit was opened. The liquid inlet flow rate was fixed while the gas flow rate was varied. The separation process was observed, and data were acquired using the ERT system and LabVIEW once the condition in the separator was observed to be steady.

\section{Results and Discussion}

\subsection{Measurement of Zero-Net Liquid Holdup-Stagnant Liquid Approach}

The measurement of zero-net liquid holdup in the separator using ERT in the case of stagnant liquid and 
flowing gas was carried out to compare with the previous measurement approaches used by other researchers. Direct measurement of the ZNLF holdup under flowing conditions obviously accounts for the effect of the liquid and gas on ZNLF holup unlike the previous approach of 'simultaneously stopping' the flow of gas to measure the liquid height while ignoring the presence of bubbles in the liquid.

Figure 3 shows the result of liquid holdup under ZNLF condition as a function of superficial gas velocity. It can be seen clearly that the liquid holdup in the separator at $250 \mathrm{~mm}$ above the separator inlet decreases as the superficial gas velocity in the separator inlet increases. This is because the liquid in the separator was "swept out" due to the momentum of the rising gas. It was observed during the test that, each time the gas flow rate was increased, a certain amount of liquid was transported out of the separator until equilibrium between the amounts of rising and falling liquid droplets was reached. The remaining liquid in the separator kept rising and falling in a chaotic manner similar to typical churn flow, but no liquid was blown out of the separator.

The implication of these results is that; as the gas velocity increases, the amount of liquid that can be tolerated in the upper part of the separator for efficient phase separation reduces. However, since the liquid phase was initially stagnant and only single-phase gas was flowing into the separator, the cross-sectional liquid holdup for each inlet gas
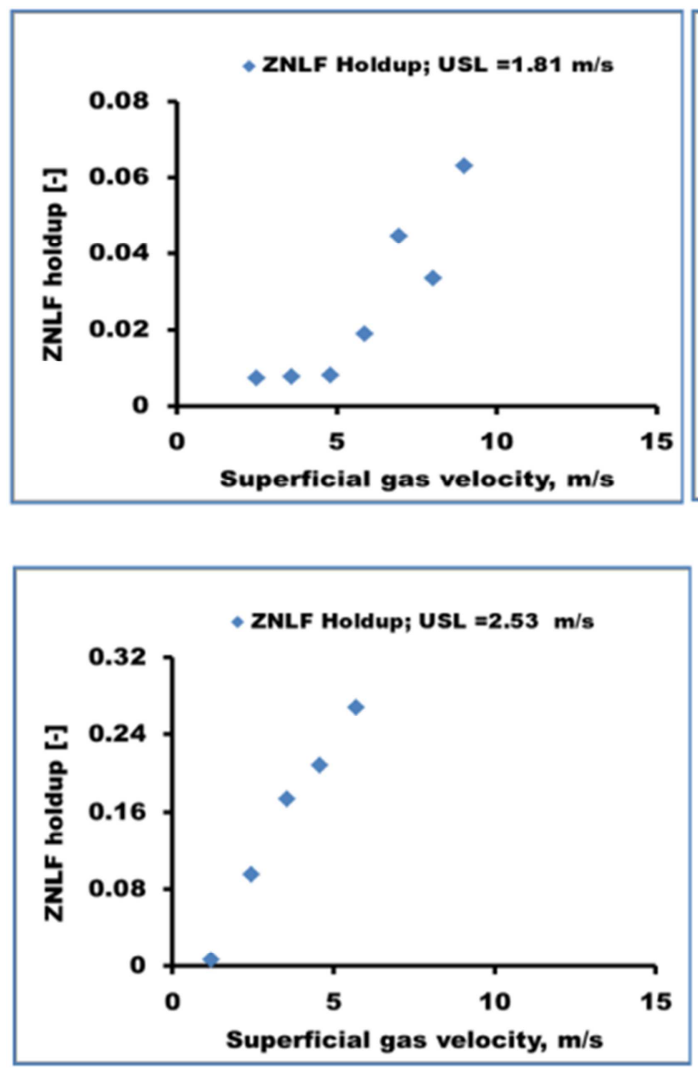

velocity may not be the same as when two-phase gas-liquid mixture enters the separator for the actual separation process.

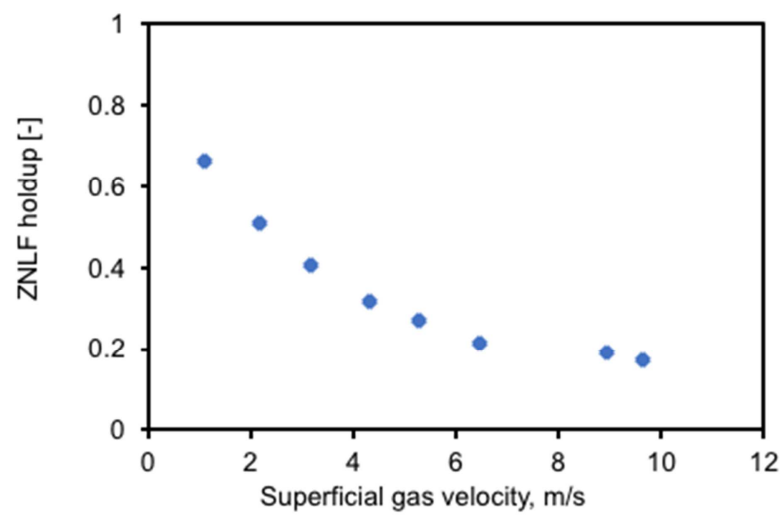

Figure 3. Stagnant liquid and flowing gas.

\subsection{ZNLF for Actual Separation Condition}

The liquid holdup during ZNLF when the separator was in normal operational mode is presented in Figure 4. The liquid holdup increases with an increase in inlet superficial gas velocity for a fixed inlet superficial liquid velocity. This is due to the corresponding increase in momentum of the twophase mixture in the separator inlet.
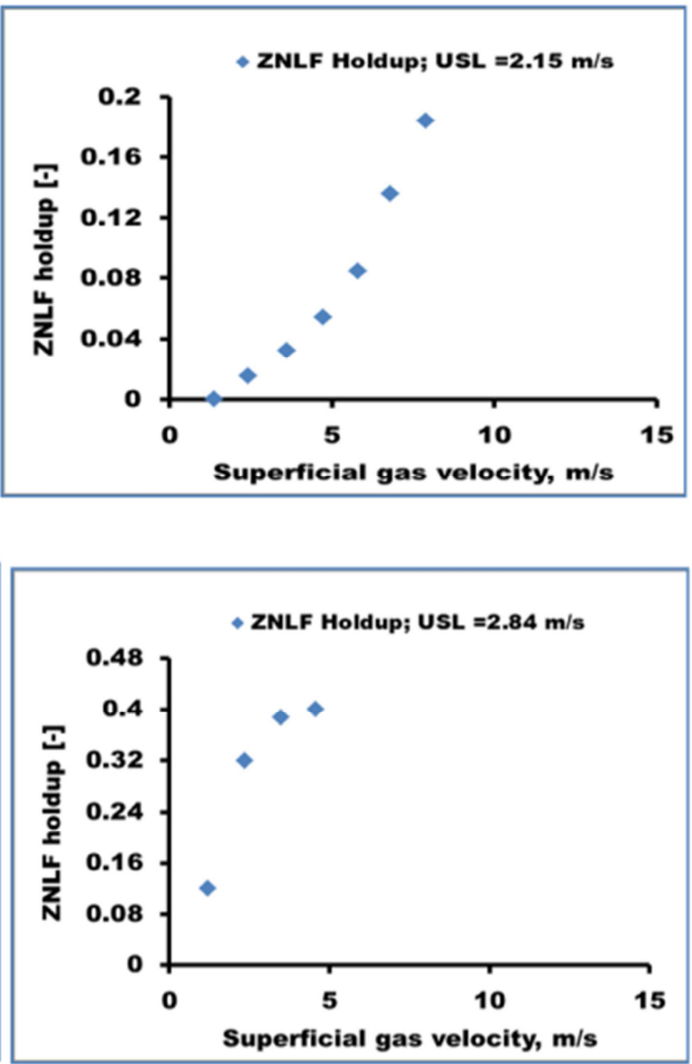

Figure 4. Liquid holdup in GLPC separator under ZNLF condition as a function of both separator inlet gas velocity, $U_{S G}=10.7 \mathrm{~m} / \mathrm{s}$ to $4.57 \mathrm{~m} / \mathrm{s}$ and $U_{S L}=$ $1.81 \mathrm{~m} / \mathrm{s}$ to $2.84 \mathrm{~m} / \mathrm{s}$.

The increase in the inlet momentum results in higher swirling intensity. Hence, liquid fraction swirls upward along with the gas in the form of swirling liquid film resulting in increasing liquid holdup. For every fixed inlet liquid 
superficial velocity, a critical condition was found where by the liquid film in the upper part of the separator became wavy and turbulent. A slight increase in gas velocity or liquid velocity above this critical operating condition resulted in LCO: liquid flowing in the gas outlet of the separator in the form of drops. The liquid holdup in the upper part of the separator for this critical condition is referred to as critical ZNLF hold. Collecting some of the ZNLF holdup data and plotting against their respective inlet gas velocity and liquid superficial velocity produced the critical ZNLF holdup curve shown in Figure 5. From Figure 5, it can be seen that the critical ZNLF holdup decreases with increasing gas superficial velocity. This is purely due to the effect of separator capacity limitation in handling high gas flow rate at high liquid flow rate efficiently. At high gas flow rate and high liquid flow rate ZNLF can no longer exist.

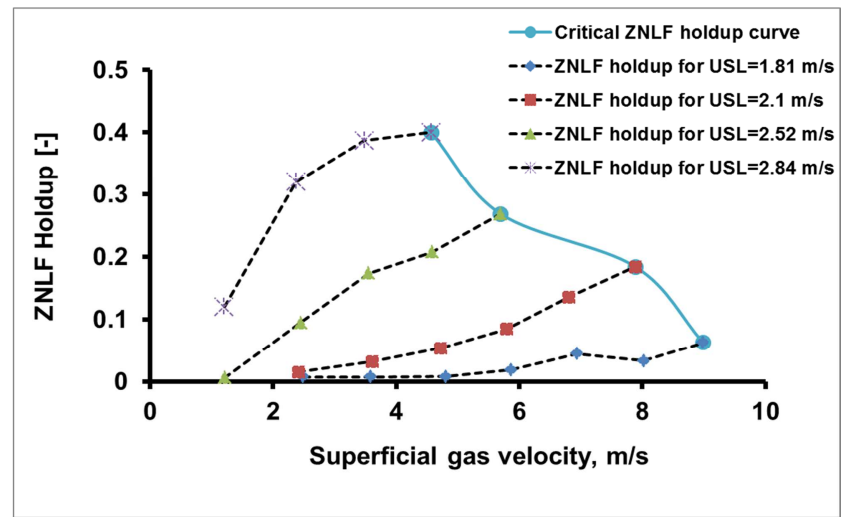

Figure 5. Critical ZNLF holdup.

\subsection{Comparison of Liquid Holdup Data with Existing Data}

In this section, the data on ZNLF holdup in gas-liquid pipe cyclone is compared with the work of Kouba et al., [8] and Arpandi et al., [10]. Kouba data was obtained by conducting an experiment using a 2" ID GLCC separator while those of Arpandi were for 3"ID GLCC separator. In Figure 6. the ZNLF holdup data of Kouba and Arpandi as well as the critical ZNLF holdup were plotted against superficial gas velocity for easy comparison. The comparison is highlighted as follows:

Kouba, Arpandi and the present ZNLF holdup data showed the same trend: critical ZNLF holdup decreases with increasing superficial gas velocity irrespective of separator size, inlet pipe inclination angle, stagnant liquid and actual separation mode.

Using the stagnant liquid procedure for the same inlet pipe inclination and separator diameter; a wide margin (up to one order of magnitude in some cases) exist between the critical ZNLF holdup measurement using ERT and the differential pressure measurement approach by Kouba et at., [8] and Arpandi et al., [10]. The ZNLF holdup during gas-liquid separation also showed a wide margin (up to one order of magnitude in some cases) between the present data and data from Kouba et at., [8] and Arpandi et al., [10]. This wide margin is expected since the measurement instrument and approach are different. The ERT measurement depends on the electrical conductivity distribution of the phases present. This means that the liquid holdup measurement reflects direct dependency on the flow rate of gas both for stagnant and fixed liquid flow rate. Moreover, research by Fransolet et al., suggests that liquid level and differential pressure measurement method shows discrepancy under churn flow regime [11]. Unfortunately, the churn flow regime dominates stagnant liquid experiment for ZNLF holdup measurement. The wide margin between the actual separation and the existing approach is expected because the effect of flowing liquid on the ZNLF holdup cannot be accounted for in the stagnant liquid procedure.

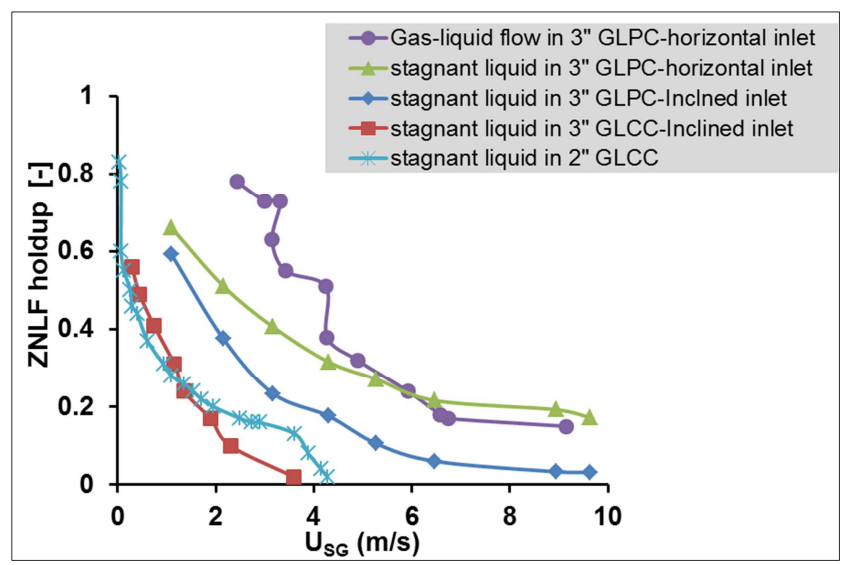

Figure 6. ZNLF holdup for stagnant liquid and flowing gas experiment in 2 "GLCC by Kouba et al., [8] and 3" GLCC by Apardi et al., [10] compared with present data.

Though one cannot discredit the result obtained, using the existing approach based on the present data but it is important to mention that under separation operating condition, the present approach could stand the test of time. The existing approach may be cheap and straightforward, but it inherently conservative in addition to the fact that progressive increment in liquid holdup as gas velocity increases before the critical holdup cannot be elucidated. Since liquid holdup has a huge influence on the pressure drop across the inlet and gas outlet of the separator, it is extremely important to be less conservative with ZNLF holdup measurement.

The present ZNLF holds measurement approach is an improvement on the existing work because the influence of inlet liquid flow rate on the amount of liquid that could be tolerated at the upper part of the separator was considered and the measurement was carried out under actual separation process. In addition, direct measurement of ZNLF holdup using ERT for actual separation takes care of all the assumptions made by the previous research. Now that ZNLF holdup has been measured directly during the actual separation process, a correlation for estimating ZNLF holdup is proposed in the next section.

\subsection{Critical ZNLF Holdup Correlation}

The existing model for predicting ZNLF in gas-liquid 
cyclonic separator was developed based on a stagnant liquid experiment rather than an actual separation condition [6-8]. Therefore, an empirical correlation for critical liquid holdup under ZNLF during actual separation condition is proposed in this section. As liquid holdup under critical ZNLF during phase separation is an important parameter in calculating mixture density for pressure drop estimation in the gas leg of the separator, it is essential that the liquid holdup prediction for ZNLF be accurate as possible. From experimental findings as presented above, the following dimensional variables were thought to affect liquid holdup $\left(\mathrm{H}_{\mathrm{LO}}\right)$ in the upper part of GLPC separator under critical ZNLF: $\Delta P, v_{t, m}, \rho_{m}, \sigma_{L}, \mu_{L}, g$, and $D_{s e p}$. The functional relationship between critical ZNLF holdup $\left(\mathrm{H}_{\mathrm{LO}}\right)$ and these variables could be represented by Equation 1.

$$
H_{L O}=f\left(\Delta P, v_{t, m}, \rho_{m}, \sigma_{L}, \mu_{L}, g, D_{s e p}\right)
$$

where $\Delta \mathrm{P}$ is pressure drop in the gas section of the separator; $v_{t, m}$ is the mixture tangential velocity; $\rho_{m}$ is homogeneous no-slip mixture density; $\sigma_{L}$ is the surface tension of liquid; $\mu_{L}$ is the dynamic viscosity of the liquid, $g$ is the acceleration due to gravity and $D_{\text {sep }}$ is the diameter of the separator.

The dimensional variables listed above have a contributing effect on the liquid holdup under ZNLF, as explained below. At a constant liquid superficial velocity liquid holdup in the upper part of the GLPC separator operating under ZNLF increases with an increase in the superficial gas velocity. The superficial gas velocity and mixture density directly represent the effect of inlet momentum on ZNLF holdup. Pressure drop affects liquid holdup in the upper part of the separator due to the increase in drag force of the gas phase. Research findings, according to Movafaghian et al., and recently by Hreiz et al., showed that liquid holdup in the upper part of GLCC increases with an increase in liquid viscosity [9-10]. The effect of reducing surface tension as published by Kolla indicates that; reducing surface tension increases the tendency of churn flow at low gas velocity [15]. Obviously, the separator geometry also has an effect on liquid holdup in the upper part of the separator. Therefore, separator geometry was considered by introducing diameter effect on liquid holdup since ZNLF holdup is defined with respect to separator cross sectional area. Gravity force effect on liquid holdup during ZNLF is important because gravity is responsible for downward liquid film drainage.

The Buckingham $\mathrm{Pi}$ theorem was applied to the dimensional variables listed above so that the variable could be grouped into dimensionless numbers. Four dimensionless groups were obtained, as presented in Equation 2.

$$
H_{L O}=f\left(\frac{\Delta P}{\rho_{m} v_{t, m}^{2}}, \frac{\sigma_{L}}{\rho_{m} v_{t, m}^{2} D_{s e p}}, \frac{\mu_{L}}{\rho_{m} v_{t, m} D_{s e p}}, \frac{g D_{s e p}}{v_{t, m}^{2}}\right)
$$

Equation 1-2 can be written in the form of well-known dimensionless numbers as:

$$
\mathrm{H}_{\mathrm{LO}}=\mathrm{f}(\mathrm{Eu}, \mathrm{We}, \mathrm{Re}, \mathrm{Fr})
$$

where $\mathrm{Eu}, \mathrm{We}, \mathrm{Re}$ and Fr represents Euler, Weber, Reynolds, and Froude number respectively.

The dataset used in developing this correlation was for separator inlet liquid superficial velocity ranging from 3.2 to $12.1 \mathrm{~m} / \mathrm{s}$ and liquid superficial velocity ranging from $1.5 \mathrm{~m} / \mathrm{s}$ to $3.8 \mathrm{~m} / \mathrm{s}$. From experimental observation and a priori knowledge of ZNLF holdup during phase separation, power law was selected as the functional relationship between the dimensionless groups and the critical ZNLF holdup as follows:

$$
H_{L O}=\beta E u^{a} W e^{b} \operatorname{Re}^{c} \mathrm{Fr}^{d}
$$

where $\beta, a, b, c$ and $d$ are coefficient and exponents respectively to be obtained by curve fitting the data. A preliminary assessment on the effect of each of the dimensionless number on the prediction using multiple nonlinear regression method produced a coefficient of zero for Weber and Reynolds number with $\mathrm{R}^{2}$ of 0.96 . This means that the contribution of Weber and Reynolds number to the prediction of critical ZNLF holdup is statistically insignificant and therefore discarded and Equation 4 becomes:

$$
H_{L O}=\beta E u^{a} F r^{b}
$$

Equation 5 is then regressed against experimental data of the liquid holdup using GRG non-linear optimisation solver in MS Excel and $\beta, a$ and $b$ were obtained as 5.8, 2.94 and 0.17 respectively with a mean square error of 0.006 . Therefore,

6 is the proposed correlation for predicting ZNLF holdup in GLPC separator, and it correlated well with experimental data.

$$
H_{L O}=5.8 E u^{2.94} \mathrm{Fr}^{-0.17}
$$

Note that, $E u=\frac{\Delta P}{\rho_{m} v_{t, m}^{2}}$ and $F r=\frac{g D_{s e p}}{v_{t, m}^{2}}$ are in SI unit.

In this work, the fluid physical properties such as viscosity and surface tension were not varied. If the experiment was conducted by varying the viscosity of water, it is expected that the ZNLF holdup would have generally varied with the viscosity. This is probably the reason why Reynold number did not show a significant effect on the performance of Equation 4. The high viscous liquid would tend to stick to the separator wall and would not return to the lower part of the separator as fast as the low viscous liquid like water. This would cause ZNLF holdup to increase for high viscous liquid compare to a low viscous liquid. However, an experiment conducted by Movafaghian et al., for stagnant liquid condition showed that variation of ZNLF holdup with viscosity is not significant [13]. This implied that the exclusion of Reynold number in Equation 4 might affect the performance of Equation 6. It may be worth verifying this by varying the liquid viscosity under separation operating condition.

The contribution of Weber number appeared insignificant in the prediction of ZNLF holdup in this work perhaps because surface tension was constant. Under ZNLF condition, droplets entrainment into the gas core would increase liquid holdup in the upper part of the separator. It is known that decreasing surface tension increases droplets entrainment [16]. This 
implied that the exclusion of Weber number in Equation 4 might narrow the application of the correlation in a situation where surface tension is expected to be constant. The author recommends that future research on this subject could look investigate the effect of varying the fluid viscosity and surface tension so as to modify Equation 6.

\subsection{Performance of the Proposed Correlation}

In this section, the proposed critical ZNLF holdup correlation is compared with the experimental data and the existing model by Arpandi et al., [10].

\subsubsection{Comparison Between the Correlation and Experimental Data}

The ZNLF holdup correlation was first compared against the measured ZNLF holdup test data and then against the separator inlet superficial liquid and gas velocity. As shown in Figure 7 , the proposed correlation predicted $72 \%$ of the data within a $10 \%$ error margin. For practical application, it will be desirable to know the range of inlet liquid and gas velocity within which the compact separator can operate. This information is also very useful in sizing the compact separator. It is based on the pretext that the proposed correlation was tested against separator inlet gas and liquid superficial velocity. First, the correlation was tested against the dataset that was used for curve fitting by the non-linear regression model.

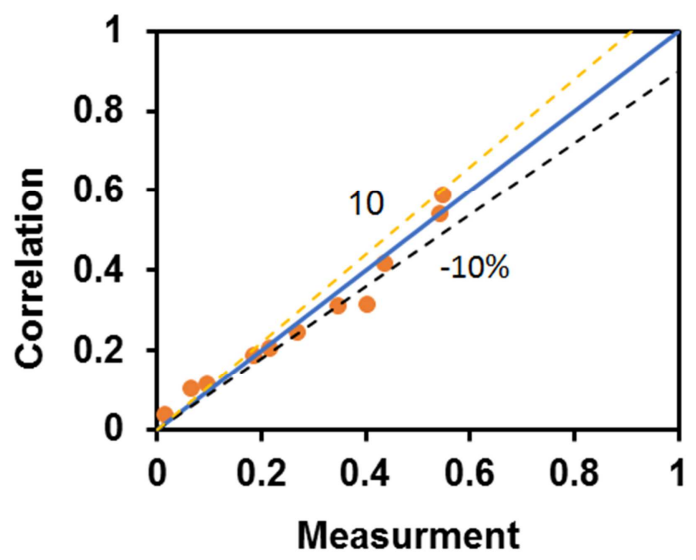

Figure 7. Comparison of correlation with critical ZNLF holdup data.

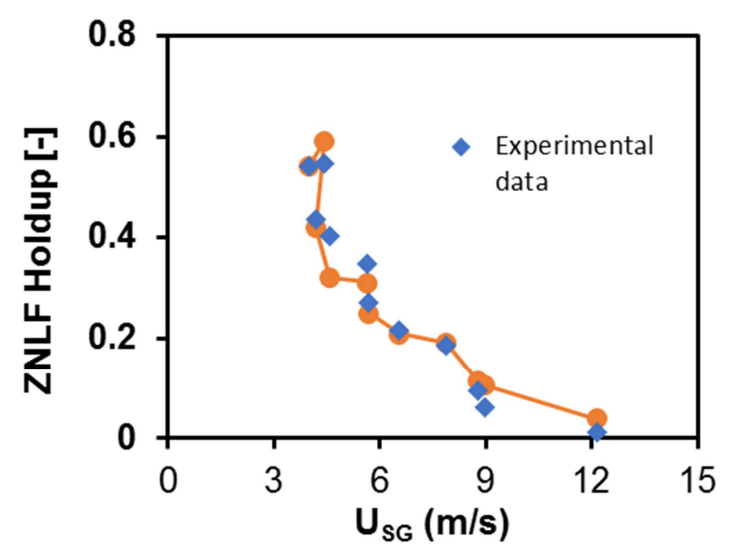

Figure 8. Comparison between critical ZNLF hold prediction and data $U_{S G}$ $=4$ to $12 \mathrm{~m} / \mathrm{s}$.

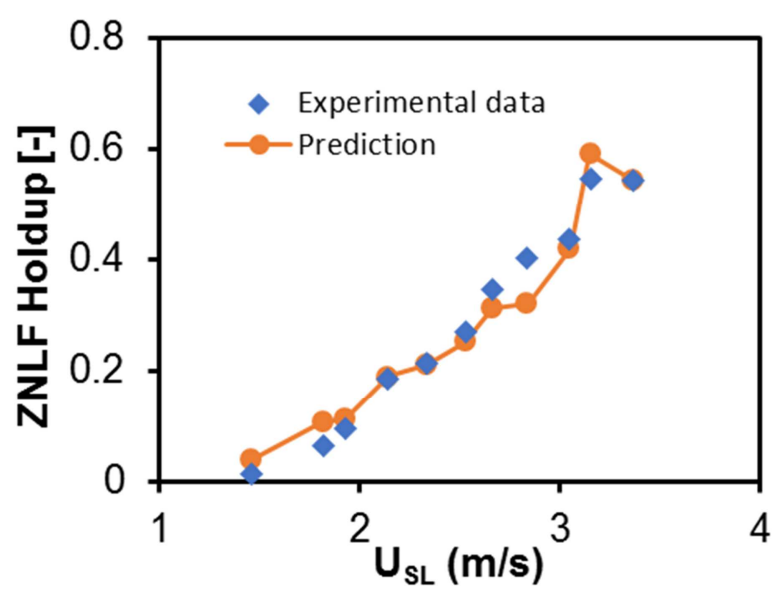

Figure 9. Comparison between critical ZNLF hold prediction and data $U_{S L}=1.5$ to $3.3 \mathrm{~m} / \mathrm{s}$.

It can be seen in Figure 8 and Figure 9 that the proposed correlation predicted the data reasonably well. It is also clear from both Figure 8 and Figure 9 that the proposed correlation accounted for the effect of gas and liquid velocity at the separator inlet. Specifically, at low gas velocity, more liquid is tolerated in the upper part of the separator, as the inlet gas velocity is within the operating envelope and capacity of the separator. Figure 9 shows that critical ZNLF holdup in the separator increase with increasing separator inlet superficial liquid velocity. However, the increase in the ZNLF holdup could mean that the separator can only permit low gas velocity; otherwise, the gas could drag the liquid easily towards the gas outlet of the separator.

\subsubsection{Comparison of the Proposed Correlation with the Existing Model}

Arpandi et al., developed a model for predicting ZNLF holdup in GLCC. This model is compared with the proposed correlation because the model is the only ZNLF holdup model that has been developed for compact cyclonic separator design [10]. The detail about the formulation of this model is presented in chapter two, and therefore, only the final version of the model is presented in Equation 7, 8 and 9.

$$
H_{L o}=\left(1-\frac{v_{S G}}{v_{G O}}\right)\left(1-\frac{L_{d}}{L_{g 1}}\right)
$$

where $v_{G O}$ is given as

$$
\begin{aligned}
& v_{G O}=C_{o} v_{S G}+0.35 \sqrt{\frac{g D\left(\rho_{L}-\rho_{G}\right)}{\rho_{L}}} \\
& L_{d}=\frac{1}{\frac{2 g}{v_{S G}^{2}}-\left(\frac{C_{d}}{2}\right)\left(\rho_{o} v_{S G}\right)^{2}\left(\frac{3}{32 \rho_{L} \sigma g}\right)}
\end{aligned}
$$

where, $v_{G O}$ is the gas velocity, which was developed from the modified Taylor bubble rise velocity, $L_{d}$ is the length of droplet region of the GLCC adopted from droplets ballistic analysis and $L_{g 1}$ is the total height above the inlet of GLCC separator. 


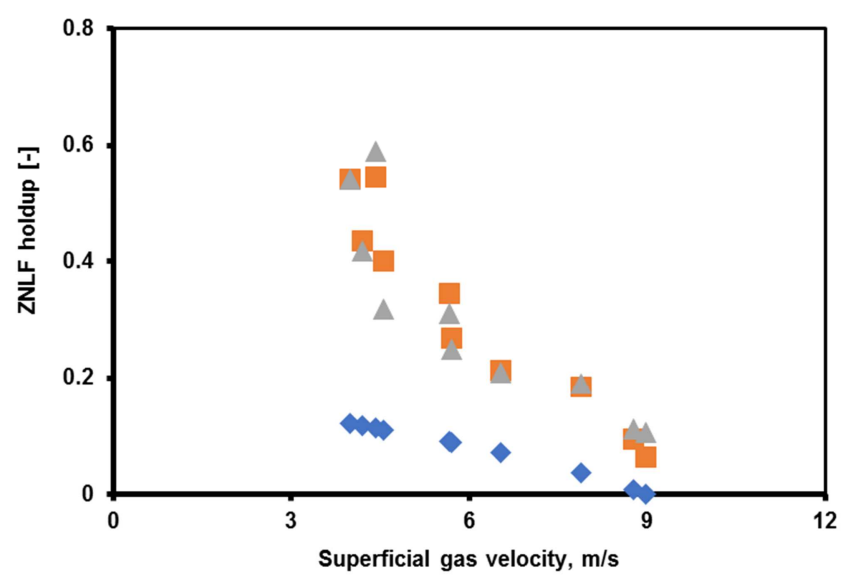

Figure 10. Comparison of Arpandi et al., [10] with measured data of ZNLF holdup obtained under actual phase separation condition and data obtained by using the proposed correlation for USG $=4.0 \mathrm{~m} / \mathrm{s}$ to $12.2 \mathrm{~m} / \mathrm{s}$.

The result of the comparison of the model with measured data as well as the proposed correlation is presented in Figure 9. This is the liquid holdup data for critical ZNLF condition. It is obvious that the model did not predict the measured data. There are several assumptions made in developing the model that are probably responsible for the error in predicting the measured data. The use of a modified Taylor bubble rise velocity, and ballistic analysis may not be ideal for GLCC. Furthermore, their assumption about the existence of slug/churn flow regime in the section above the inlet of the separator only holds during typical two-phase flow condition which is unlikely under the ideal operating condition of the separator. Under ZNLF during the separation process, the flow regime is always swirling annular or light drops in the section where ZNLF holdup exists. Churn flow was observed when ZNLF ceased because of liquid carryover. Taylor bubble rises velocity could be a good assumption when the liquid is stagnant but not during the separation process.

\section{Conclusion}

Liquid holdup under ZNLF for a stagnant liquid condition was measured using electrical resistance tomography. The trend of present data of ZNLF holdup under stagnant liquid condition agrees with that reported by Kouba et al., [4] and Apardi et al., [6]. However, quantitatively, their data are not comparable with the present data, as the effect of inlet liquid flow on ZNLF was not considered in their work. ZNLF holdup under actual phase separation condition in gas-liquid pipe cyclonic separator was measured using electrical resistance tomography. A critical ZNLF was identified above which liquid was seen in the gas outlet in the form of visible liquid droplets. The liquid holdup that existed during the critical ZNLF is called critical ZNLF holdup. By grouping some of the critical ZNLF holdup, a trend was realised that agreed with existing data by Kouba et al., and Apardi et al., that is: the critical ZNLF holdup decrease with increasing separator inlet superficial gas velocity $[4,6]$. Additionally, it was found that the critical ZNLF holdup increases with increasing separator inlet superficial liquid velocity. A correlation was proposed for predicting critical ZNLF holdup in gas-liquid pipe cyclonic separator under actual phase separation process. Euler and Froude number were found to have the most significant effect on critical ZNLF holdup. The proposed correlation agreed with $70 \%$ of the non-critical ZNLF holdup data with $20 \%$ error margin. The prediction of the experimental data by the proposed correlation compared to the model by Arpandi et al., did not match quantitatively but showed a similar trend [4].

\section{References}

[1] S. M. M. Sarshar, "The Applications of a Novel Compact Separation System in UBD and MPD Operations," IADC/SPE Managed Pressure Drilling and Underbalanced Operations Conference and Exhibition. Society of Petroleum Engineers, San Antonio, Texas, USA, p. 12, 2013.

[2] C. A. Capela Moraes and S. Shaiek, "Subsea Separation: The Way to Go for Increasing Water Production and NPV Optimization," Offshore Technology Conference. Offshore Technology Conference, Houston, Texas, p. 19, 2019.

[3] H. Li, J. Chen, J. Wang, J. Gong, and B. Yu, “An improved design method for compact vertical separator combined with the theoretical method and numerical simulation," J. Pet. Sci. Eng., vol. 173, pp. 758-769, 2019.

[4] H. Refsnes, M. Diaz, and M. Stanko, "Performance evaluation of a multi-branch gas-liquid pipe separator using computational fluid dynamics," J. Pet. Explor. Prod. Technol., no. $0123456789,2019$.

[5] H. S. Skjefstad and M. Stanko, "Experimental performance evaluation and design optimization of a horizontal multi-pipe separator for subsea oil-water bulk separation," J. Pet. Sci. Eng., vol. 176, pp. 203-219, 2019.

[6] T. Krebs et al., "Debottlenecking of FPSO Facilities by Compact Separators," Abu Dhabi International Petroleum Exhibition \& Conference. Society of Petroleum Engineers, Abu Dhabi, UAE, p. 14, 2016.

[7] L. Kanshio, Sunday., Yeung, Hoi., Liyun, “The Experimental Study of Liquid Holdup in Gas-Liquid Pipe Cyclonic Separator using Electrical Resistance Tomography and Wire Mesh Sensor," in 17th International Conference Multiphase Production Technology, 2015.

[8] G. E. Kouba, O. Shoham, and S. Shirazi, "Design and performance of gas-liquid cylindrical cyclone separators," in Proceedings of the BHR Group 7th International Meeting on Multiphase Flow., Cannes, France, 1995, pp. $307-327$.

[9] S. S. Kolla, M. P. Karpurapu, R. S. Mohan, and O. Shoham, "Mechanistic Modeling of Dynamic Zero-Net Liquid Holdup (ZNLH) in Gas-Liquid Cylindrical Cyclone (GLCCO) Separator," no. 52101. p. V007T09A016, 2018.

[10] I. Arpandi, A. R. Joshi, O. Shoham, S. Shirazi, and G. E. Kouba, "Hydrodynamics of Two-Phase Flow in Gas-Liquid Cylindrical Cyclone Separators," in SPE Annual Technical Conference \& Exhibition held in Dallas, U. S. A., 22-25 October 1995., 1996. 
[11] E. Fransolet, M. Crine, G. L'Homme, D. Toye, and P. Marchot, "Analysis of electrical resistance tomography measurements obtained on a bubble column," Meas. Sci. Technol., vol. 12, no. 8, pp. 1055-1060, 2001.

[12] R. W. Duncan and S. L. Scott, "Vertical zero net liquid flow: effects of high-pressure on holdup," in BHR group conference publication, 1998, vol. 31, pp. 43-60.

[13] S. Movafaghian, J. a Jaua-marturet, R. S. Mohan, and O. Shoham, "The effects of geometry, fluid properties and pressure on the hydrodynamics of gas-liquid cylindrical cyclone separators," vol. 26, pp. 999-1018, 2000.
[14] R. Hreiz, R. Lainé, J. Wu, C. Lemaitre, C. Gentric, and D. Fünfschilling, "On the effect of the nozzle design on the performances of gas-liquid cylindrical cyclone separators," Int. J. Multiph. Flow, vol. 58, pp. 15-26, Jan. 2014.

[15] S. S. Kolla, "Liquid carry-over in Gas-Liquid Cylindrical Cyclone (GLCCC) compact separators for three-phase flow," The University of Tulsa, 2007.

[16] M. Bothamley, "Gas/Liquid Separators: Quantifying Separation Performance," Oil Gas Facil., no. February, 2013. 